\title{
ESTIMATIVA DO FLUXO DE CALOR NO SOLO PARA DIFERENTES PROFUNDIDADES
}

\author{
Marcos Corrêa Silveira ${ }^{1}$, Tamíres Zimmer ${ }^{1}$, Virnei Silva Moreira ${ }^{2}$, Débora Regina Roberti ${ }^{1}$. \\ ${ }^{1}$ Departamento de Física, Universidade Federal de Santa Maria, Santa Maria - RS. \\ ${ }^{2}$ Universidade Federal do Pampa, UNIPAMPA, Itaqui - RS.
}

\section{RESUMO}

Neste trabalho o fluxo de calor no solo em área de cultivo de arroz irrigado no sul do Brasil é estimado utilizando a Lei de Fourier com um valor de condutividade térmica do solo descrito na literatura, e comparado com os dados experimentais para uma camada superficial, representando de forma satisfatório os dados experimentais. O perfil do fluxo de calor no solo nas camadas entre 2.5, 5, 10, 20 e $50 \mathrm{~cm}$ de profundidade é estimado e mostra que o fluxo de calor no solo nas diferentes profundidades são mais elevados para o período de pousio, embora sendo no inverno, que nos periodos de cultivo com lamina d'água, sendo este cultivo de verão, demonstrando assim que a lamina d'água isola o solo das grandes mudanças diárias de temperatura.

\section{SUMMARY}

In this work the heat flow in the soil in an area of irrigated rice cultivation in southern Brazil is estimated using Fourier's law with a thermal conductivity of the soil described in the literature, and compared with experimental data for a surface layer, representing so satisfactory experimental data. The profile of the heat flux in layers around 2.5, 5, 10, 20 and $50 \mathrm{~cm}$ depth is estimated and shows that the heat flux into the soil at different depths are higher for the fallow, whilst in winter that in periods of cultivation with water blade, this being summer crop, thus demonstrating that the lamina water insulates the soil from large daily temperature changes.

\section{INTRODUÇÃO}


No Rio Grande do Sul, áreas de várzea de rios são geralmente utilizadas para o cultivo de arroz. Numa cultura de arroz irrigado, o solo passa por diferentes fases ao longo do ano, alternando entre período alagado com arroz e período de pousio. No período alagado com arroz a planta fica coberta, por inundação, com uma lâmina de água de 5 a $10 \mathrm{~cm}$ na maior parte do seu ciclo e no período de pousio a área fica apenas com os resíduos culturais da colheita, ou plantas esparsas e eventuais alagamentos típicos de várzeas de rios. Entender como o fluxo de energia no solo se comporta ao longo do ano para uma área de várzea de rio e com cultivo agrícola tal como o arroz irrigado, tem importância fundamental para estudos de balanço de energia. O objetivo deste trabalho é estimar o fluxo de calor no solo para diferentes profundidades ao longo de um ano em uma área de cultivo de arroz irrigado no município de Paraíso do Sul-RS.

\section{MATERIAIS E MÉTODOS}

O sítio experimental de cultivo de arroz irrigado estava localizado em Paraíso do Sul, RS (2944'39,6"S; 53ㅇ'59,8"W, 108m).Dados experimentais da temperatura do solo foram coletados a 2.5, 5, 10, 20 e $50 \mathrm{~cm}$ profundidade e do fluxo de calor no solo foram coletados a $7 \mathrm{~cm}$ de profundidade. O período do estudo foi de junho 2003 a julho de 2004.

O fluxo de calor no solo $(\mathrm{G})$ pode ser estimado usando a temperatura do solo experimental (T) e a condutividade termal do solo $(K s)$ como na lei de Fourier:

$$
G=-K s \frac{\left(T_{2}-T_{1}\right)}{\left(Z_{2}-Z_{1}\right)}
$$

onde $T_{2}$ e $T_{1}$ são as temperaturas do solo nas profundidades do solo $\mathrm{Z}_{2}$ e $\mathrm{Z}_{1}$, respectivamente, sendo $\mathrm{Z}_{2}>\mathrm{Z}_{1}$. As unidades são: $\mathrm{G}\left(\mathrm{Wm}^{-2}\right), K s\left(\mathrm{Wm}^{-1} \mathrm{~K}^{-1}\right), \mathrm{T}(\mathrm{K}), \mathrm{Z}(\mathrm{m})$. O fluxo de calor no solo observado $(\mathrm{Fg})$ foi comparado com o fluxo de calor no solo estimado $(\mathrm{G})$, usando um valor de $K s$ conhecido da literatura para esse tipo de solo em condições saturadas $(K s=1.58)$ (Oke, 1988).

\section{RESULTADOS E DISCUSSÃO}

A figura 1a, mostra a média diária para o período do estudo para o fluxo de calor no solo estimado (G) utilizando a equação (1) entre as profundidades $Z_{1}=5 \mathrm{~cm}$ e $Z_{2}=10 \mathrm{~cm}$ e o fluxo de calor no solo observado $(\mathrm{Fg})$ a $7 \mathrm{~cm}$ de profundidade. $\mathrm{O}$ erro quadrático médio foi de 
13.28 $\mathrm{Wm}^{-2}$ e o desvio padrão para (G) estimado foi de $34.35 \mathrm{Wm}^{-2}$, e para (Fg) observado foi $31.83 \mathrm{Wm}^{-2}$. Desta forma, a estimativa do fluxo de calor no solo representa de forma satisfatória os dados experimentais. Por este motivo, este método será utilizado para calcular o fluxo de calor no solo para diferentes profundidades (conforme Tabela 1), obtendo-se, assim, o perfil vertical do fluxo de calor no solo típico de uma região de várzea de rio (Figura 1b).
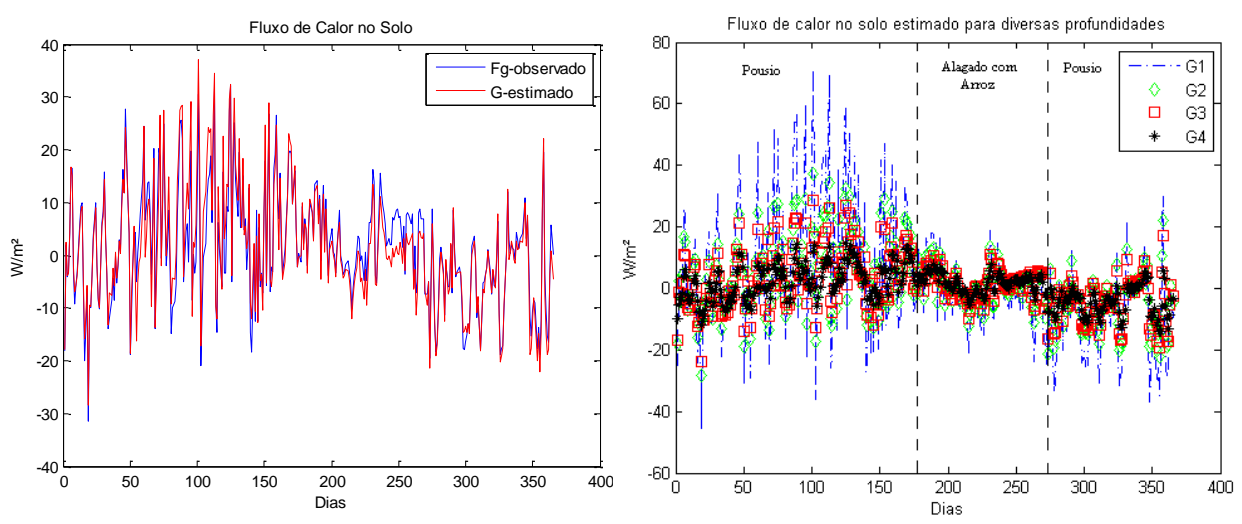

(a)

(b)

Figura 1- Média diária do fluxo de calor no solo (a) estimado e observado na camada superficial; (b) estimado utilizando a eq. (1) para diferentes profundidades.

No período do Arroz irrigado (de Dezembro á Março), o solo está coberto com vegetação e uma lamina de água de 7 á $10 \mathrm{~cm}$, que influência na variação do fluxo de calor no solo, não somente na camada superficial mas como também nas outras camadas mais profundas. A variação vertical do fluxo de calor no solo neste período é menor (ver Figura 1b), ou seja, próximo da superfície o fluxo é praticamente o mesmo que a $50 \mathrm{~cm}$ e com valores próximos de zero, ou seja, não ocorre uma grande variação de temperatura no solo neste período, devido a lamina d'água, que atua como um isolante entre o solo e a atmosfera.

No período de pousio a área fica apenas com os resíduos culturais da colheita, ou plantas esparsas, ficando sujeito a grandes variações térmicas diárias nas camadas superficiais. Como o solo do sítio experimental tem características de solo arenoso, ele tende a apresentar 
maiores amplitudes térmicas diárias nas camadas superficiais e menores em profundidade, resultando assim num maior variação vertical do fluxo de calor no solo nas camadas próximas da superfície.

A Tabela 1 apresenta os valores médios do fluxo de calor no solo em cada dois períodos distintos: Período alagado com Arroz e Período de Pousio. Pode-se perceber que nas camadas superficiais os valores do fluxo de calor no solo foram mais elevados comparados com as camadas mais profundas nos dois períodos. No entanto, no período com arroz, que é cultivado no verão, os valores do fluxo de calor no solo são menores que no período de pousio, que é no inverno e primavera. Na ultima camada, entre 20 e $50 \mathrm{~cm}$, nota-se que no período de pousio o fluxo é negativo, representado que o aquecimento da superfície não atinge esta camada, e o subsolo aquece esta camada.

\begin{tabular}{|c|c|c|c|c|}
\hline & $\mathrm{Z}_{1}(\mathrm{~cm})$ & $\mathrm{Z}_{2}(\mathrm{~cm})$ & Período alagado com Arroz & Período de Pousio \\
\hline $\mathrm{G}_{1}$ & 2.5 & $5_{1}$ & 65.33 & 101.88 \\
\hline $\mathrm{G}_{2}$ & 5 & $10_{2}$ & 32.60 & 53.24 \\
\hline $\mathrm{G}_{3}$ & 10 & 20 & 11.82 & 29.65 \\
\hline $\mathrm{G}_{4}$ & 20 & 50 & 0.30 & -0.29 \\
\hline
\end{tabular}

Tabela 1: Valores médios do fluxo de calor em cada camada $\left(\mathrm{Wm}^{-2}\right)$, para os períodos analisados.

\section{CONCLUSÃO}

O fluxo de calor no solo para as regiões de várzea de rio do sul do Brasil pode ser bem representado utilizando a equação de Fourier e utilizando um valor de condutividade térmica, $K s$, conhecido da literatura para esse tipo de solo em condições saturadas ( $K s$ =1.58). Os valores do fluxo de calor no solo nas diferentes profundidades são mais elevados para o período de pousio, embora sendo no inverno, que nos períodos de cultivo com lamina d'água, sendo este cultivo de verão, demonstrando assim que a lamina d'água isola o solo das grandes mudanças diárias de temperatura.

\section{BIBLIOGRAFIA}

OKE, T. R. Boundary Layer Climate. 2nd Edition, Routledge, 1987. 43-44p 